\title{
DESPEJO POR MAU USO DO PRÉDIO LOCADO
}

\author{
Antônio Cláudio da Costa Machado \\ Professor Assistente junto ao Departamento de Direito Processual da \\ Faculdade de Direito da USP
}

\begin{abstract}
Resumo: O presente estudo tem por escopo primordial o exame da violação pelo inquilino do dever de tratar do prédio locado como se fosse seu. Parte-se da visão jurisprudencial acerca da matéria somada à pouca doutrina construída sobre o tema para se chegar a algumas conclusões assim elencadas: o dever genérico do art. 21 da Lei $6.649 / 79$ pode ser transferido ao locatário contratualmente; o contrato de locação pode estabelecer detalhadamente como o prédio deve ser cuidado; a análise da gravidade da infração só tem lugar quando se tratar de dever legal ou contratual não especificado; na falta de exigência do locatário de relação escrita, presume-se que o prédio foi entregue em bom estado de conservação; a ação de despejo pode ser proposta no curso da relação locatícia; o locador pode cumular ao pedido de despejo o de indenização; e, finalmente, não é necessária qualquer notificação para que se viabilize a ação de despejo por mau uso do prédio locado.
\end{abstract}

Summary: The present study has as main scope the examination of the lessee violation to the duty of taking care of the building as it were his. We start by the exame of the jurisprudencial vision about the matter and also of the insuficient doctrine formed respecting the subject in order to get to some conclusions that are the folowing: the generical duty established by the art. 21 of the Law n. $6.649 / 79$ can be transfered by contract to the lessee; the renting contract can establich detailedly how the lessee must take care of the building; the exame of the violation gravity takes place only when the legal duty or the non specified contractual duty is considered; in the lack of the lessee exigency for the written rol, the law presumes that the building was delivered in good shape of conservation; the action to recover the building can be deducted in the course of the reating contract; the lessor can request, besides the building recovery, indemnization; and finally, it is not necessary any comunication in order to make possible the action to recover the building irregularly used.

Unitermos: Locação de Imóveis; Ação de Despejo.

1. Autoriza o art. 51 da Lei $6.649 / 79$ a rescisão dos contratos de locação nas hipóteses previstas pelo art. 52 que prescreve: "O despejo será concedido:... II- se o locatário infringir obrigação legal ou cometer infração a obrigação contratual". Quanto à infringência à obrigação legal, pratica-a o inquilino que violar qualquer dos deveres elencados no art. 19 da mesma lei dentre os 
quais se encontra o estabelecido no inciso I que reza: ‘a servir-se do prédio locado para o uso convencionado... devendo tratá-lo com o mesmo cuidado, como se fosse seu". A violação a este último dever caracteriza o que a doutrina e a jurisprudência denominam comumente de "mau uso do prédio locado". Examinemos a figura.

2. A regra esculpida no final do inciso I do art. 19 da Lei do Inquilinato, em sua expressão, é quase que reprodução literal do inciso I do art. 1.192 do Código Civil que dispõe competir ao locatário "servir-se da coisa alugada para os usos convencionados... bem como a tratá-la com o mesmo cuidado como se sua fosse". Sobre a obrigação CLÓVIS BEVILAQUA já doutrinara dizendo: "Entende-se que o dono zela as suas coisas. Não servirá, porém, de escusa a abusos e desleixos, com que trate o locatário, as suas próprias coisas". E prossegue afirmando que "a sua responsabilidade abrange atos praticados por seus prepostos, pessoas de sua família e sublocatários" (Código Civil Comentado, Francisco Alves, 1953, vol. IV, pág. 362 e 363).

A liçāo do mestre torna patente a objetividade do que se deve entender por tratar da coisa "com o mesmo cuidado, como se sua fosse". Trata-se do cuidado usual, do zelo próprio, normal, dedicado por alguém a uma coisa que é sua, podendo-se invocar aqui o objetivo paradigma do "bonus pater familie". $\mathrm{O}$ inquilino que não cuide da coisa como um diligente proprietário infringe, portanto, obrigação legal, mesmo que o seu zelo normal esteja abaixo deste parâmetro idealizado. E que "utilização normal" é considerada pela lei aquela que realiza o "proprietário cuidadoso" na lição de TUCCI-VILLAÇA (Tratado da Locação Predial Urbana, Saraiva, 1980, vol. I, pág. 230).

Deixa clara, ainda, o insígne CLÓVIS a extensão da responsabilidade do locatário perante o locador: viola a lei o inquilino que permite, expressa ou tacitamente, que seus serviçais, familiares ou sublocatários usem a coisa locada sem emprego da diligência própria de um senhorio cuidadoso.

Praticados, assim, atos pelo inquilino que se qualifiquem como "mau uso do prédio locado" e, por conseguinte, como infringentes da obrigação de "cuidar, como se fosse seu", nasce para o locador o direito à rescisão do contrato, o que se realiza pela propositura da ação de despejo (art. 19, inciso I, c.c. 52, incisco II, da Lei 6.649/79). Para ilustrar com algumas situaçōes concretas o fato gerador do direito à rescisão por mau uso trazemos à colação algumas decisōes que, embora antigas, se prestam perfeitamente a este mister: "DESPEJO - Infração de obrigação legal e contratual - Mau uso do prédio locado - Falta de limpeza e de conservação, além de transformação não autorizada pelo senhorio - Procedência da ação intentada no curso do contrato - Recurso provido".

"O mau uso do prédio durante a locação representa infração do locatário aos seus deveres normais”. (RT 371/207, Ap. 78.031, TASP 5a.C.C., julg. em 04/03/66). 
Examine-se, ainda, esta outra decisão: “DESPEJO - Infração de obrigaçāo legal - Alteração do imóvel pelo locatário, embora sem lhe alterar a estrutura - Infringência caracterizada - Ação procedente".

"O locador não está obrigado a suportar, da parte do locatário, o uso indiscriminado e prejudicial ao imóvel".

"Está implícito em todo contrato de locação, seja escrito ou nāo, o dever do locatário de zelar pela conservação da coisa locada e de mantê-la na mesma situação" (RT 369/157. Ap. 131.346, TASP, 5a. C.C., julg. em 03/04/1964, Rel. Des. Góes Nobre).

Ou esta: "DESPEJO - Infração legal - Locatário que danifica o imóvel e não atende a notificações para repará-lo - Ação procedente em face das provas - Aplicação do art. 15, n.X, da Lei no 1.300 e art. 1.193 do Código Civil.

A falta de zelo e de cuidado do locatário, que assim danifica o prédio, pode ensejar ao locador o direito de rescindir o contrato de locação" (RT 348/298. Ap. 57.996, 1a. C.C. TASP, julg. em 23/04/1963, rel. Juiz Ribeiro dos Santos).

As decisōes acima aludidas, apesar de claríssimas, podem suscitar alguns questionamentos à luz da Lei do Inquilinato em vigor. Por isso, sentimo-nos obrigados a esclarecer.

3. Prescrevem os arts. 21 e 22 da Lei 6.649/79: "Art. 21. Incumbem ao locador todas as reparações de que o prédio necessitar"; "Art. 22. O locatário é obrigado a fazer por sua conta, no prédio, as reparaçōes de estragos a que der causa desde que nāo provenham do uso normal".

As regras transcritas - reproduções quase literais do disposto no art. 1.206 e seu parágrafo único do Código Civil - importam sobremaneira ao tema "sub apretiationes", haja vista que estabelecem as fronteiras do território dentro do qual o mau uso vai poder se verificar: por um lado, a fronteira representada pelo dever genérico do locador de reparar e, de outro, a limitação imposta pelo uso normal que torna os estragos dele resultantes de inteira responsabilidade do locador (circunstância esta que também é explicitada pela parte final do inciso IV do art. 19 da Lei do Inquilinato). Ocorre, entretanto, que este estreitamento legal das obrigaçōes do inquilino pode ceder ante uma previsão contratual expressa em contrário. São freqüentes em instrumentos de avenças locatícias cláusulas que invertem a responsabilidade de conservaçāo do prédio, impondo-a, com inúmeros detalhes e minúcias, ao locatário.

Nem se argumente, por outro lado, contra o caráter dispositivo das normas contidas nos arts. 21 e 22 da Lei $6.649 / 79$ por não tercm estas reproduzido "ip- 
sis literis" o art. 1.206 do Código Civil que alude expressamente, no seu "caput", à ressalva "salvo cláusula expressa em contrário". À lei inquilinária pareceu despiciendo ressalvar que os contratantes podem disciplinar diferentemente suas obrigações quanto a esse aspecto, já que nenhum interesse de ordem pública se encontra envolvido na questão. Vale a pena lembrar a lição de TUCCI-VILLAÇA a respeito da relação existente entre o Código Civil e a Lei 6.649 neste diapasão: "De qualquer modo, é de ponderar-se que, com a inclusão do enunciado do art. 21 no contexto do Diploma legal comentado, ratificou o legislador do inquilinato a aplicabilidade da antiga regra do nosso Código Civil às locações prediais urbanas..." (op. cit., vol. I, pág. 248).

Assim, tem plena aplicação, ainda hoje, a decisão de 1963 - a que já fizemos referência linhas atrás - que julgou procedente pedido de despejo por mau uso constando da motivação que deixando injustificadamente de manter o prédio em bom estado de conservação, infringia a inquilina o contrato segundo o qual não só as chamadas reparaçōes locativas ficavam a cargo da locatária, mas também todas as outras desde que não importassem na segurança do prédio (RT 348/298). É que dada a dispositividade do art. 1.206 - e dos atuais 21 e 22 da Lei $6.649 / 79$ - pode ser validamente transferido por contrato ao inquilino o dever genérico de zelo e conservação do prédio, o que inclui evidentemente, a responsabilidade pelos chamados reparos locativos (que já são seus no silêncio do contrato) ainda que estes decorram do tempo e do uso normal. Para esta inversão de responsabilidade já chamava a atenção EDUARDO ESPINOLA há três décadas dizendo: "Não havendo estipulação contratual, o locatário só é obrigado a fazer, por sua conta, no prédio, as reparações de estragos não resultantes, como conseqüência natural, da ação do tempo ou do uso normal" (Manual do Inquilinato, Rio, 1959, 2ª ed., Borsoi, pág. 99). Ora, da lição infere-se que havendo estipulaçāo em contrário, não só os pequenos reparos, mas também aqueles oriundos do tempo ou uso normal são da responsabilidade do locatário.

Sobre as "reparaçōes locativas" especificamente - conceituadas como os pequenos reparos de estragos causados pelo inquilino - informa-nos CLÓVIS BEVILAQUA que alguns Códigos Civis de seu tempo chegaram a descer a minúcias para indicar quais seriam os estragos que corresponderiam às reparações locativas. Diz ele “... Fabio Leal propôs alguma coisa neste sentido... a colocação de fechaduras, substituição de vidros quebrados... Mas essa indicação era apenas exemplificativa" (op. cit., vol. IV, pág. 386). Outros exemplos podemos mencionar tais como tacos soltos, falta de trincas, portas deterioradas pela água, espelhos de interruptores quebrados, azulejos soltos, piso de cozinha quebrado, calhas entupidas, etc. A responsabilidade por tais reparos - repita-se - é do inquilino ainda que o contrato nada preveja (art. 1.206, par. único, do C.C. e 22 da Lei 6.649/79). Se, de outra sorte, a avença locatícia inverte expressamente a responsabilidade da conservação, que como vimos é possível, não só estes pequenos reparos, mas outros de maior significado são impostos 
indubitavelmente ao inquilino. Elucidativo quanto ao aspecto fático dos estragos numa hipótese de má conservação é o acórdão atrás referido que, como parte de sua fundamentação, deixou consignado: "São inúmeras as telhas e os vidros quebrados. Os lavatórios estão em péssimo estado de conservação, apresentam o piso de cerâmica danificado, azulejos quebrados, espelhos interruptores inutilizados, as válvulas hidra e o sifão estragados, registros quebrados, bacia do mitório em péssimo estado, etc.". E conclui, a seguir: "Em suma, por não trazer o imóvel locado em bom estado de limpeza e conservação... os peritos, em maioria, afirmaram que a locatária estava fazendo mau uso do prédio, em face das cláusulas $6 a$. e 7a. do contrato... Ora, a obrigação contratual da ré não era apenas a de restituir o imóvel em bom estado, mas, também, a de conservá-lo, o que, evidentemente, não fez. Houve, assim, infração e a ação é procedente..." (RT 371/207. Ap. 78.031, TASP, 5a. C.C., julg. em 04/03/1966, Rel. Juiz Carvalho Filho)

4. Outro ponto importante para a compreensão da responsabilidade do inquilino pela conservação do imóvel é o concernente à gravidade da infração, cuja repercussão vai depender da origem legal ou contratual da obrigação de conservar.

Estudando o assunto, e especificamente a evolução dos preceitos disciplinadores das infrações a contratos de locação, ensinam-nos TUCCI-VILLAÇA que "a orientação legislativa, nesse sentido, sempre foi a de determinar a gravidade da infração como pressuposto do despejo", nada significando a supressão do vocábulo "grave" no inciso II do art. 11 da Lei 4.494/64 (op. cit., vol. II, pág. 644 e 645). Da lição, conclui-se que as pequenas faltas cometidas pelo inquilino, ou seja, aquelas violações isoladas de pouca importância - como v.g. o não reparo de um vidro trincado, de uma pintura parcialmente descascada, a não limpeza de uma parede muito tocada por mãos ou a não recolocação de um ou dois azulejos - não constituem por si só infraçōes capazes de gerar o direito do locador à rescisão do contrato por mau uso.

Entretanto, parece conveniente lembrar a observação que fez ARRUDA CAMPOS, "apud" TUCCI-VILLAÇA, de que, quanto ao requisito da gravidade, "a exigência é feita somente no caso de violação de cláusulas contratuais, uma vez que outras, relativas à burla da lei, são uniformemente enquadráveis entre as faltas que autorizam a rescisão" (op. cit., vol. II, pág. 645). Entendemos bem a assertiva: tudo vai depender da maior ou menor objetividade da infração cometida; a questão da gravidade não se coloca, via de regra, nas hipóteses de infração legal, tais como o abuso no direito de purgar a mora, a cessão, sublocação ou empréstimo não autorizados, a alteração da destinação contratual do imóvel, o descumprimento da obrigação de não abandonar o imóvel, de respeitar a convenção de condomínio ou de substituir o fiador insolvente; pelo contrário, o problema da gravidade se impõe comumente quando se discutam infrações contratuais como a de conservar genericamente o imóvel. É claro, a 
objetividade da violação ao dever de não ceder, não abandonar ou ao de substituir o fiador é muito maior do que a objetividade da infração ao dever de conservar ou zelar, imposto genericamente pelo contrato. Agora, se o contrato de locação transfere ao locatário o dever de conservação e zelo discriminando minuciosamente as espécies de reparo que ficam sob a responsabilidade, é evidente que a questão da gravidade cai no vazio, dispensando-se, assim, o magistrado de ter de apreciá-la segundo o seu prudente arbítrio. Imagine-se, por exemplo, que o contrato imponha expressamente ao inquilino, o que é freqüente, a obrigação de consertar torneiras, substituir vidros, reparar ou substituir aparelhos de instalação de água, de luz, telefone, de pintar e conservar e ou reparar rebocos, fogões, louças, aquecedores, instalaçōes sanitárias e tudo mais que se encontre no imóvel locado, além do dever de mantê-lo em perfeitas condições de higiene e limpeza. A objetividade das infraçōes a tais deveres, numa hipótese como esta, é tamanha que nāo há de se cogitar da questão da gravidade para çue o contrato possa ser rescindido via ação de despejo, desde, como é 'óbvio, que a perícia apure a existência de qualquer desses fatos (perícia, não simples orçamentos: Ap. 187.647, 2a. C. II TACSP, julg. em 05/02/1986, Rel. Juiz Walter Moraes).

5. Controvérsia interessante que pode nascer no bojo do processo da ação de despejo por infraçāo ao dever legal ou contratual de zelar pelo imóvel, é a oriunda da contestação apresentada pelo locatário em que este se defenda alegando que, quando do estabelecimento da locação, o prédio já se encontrava em estado precário. Que eficácia teria tal defesa? Reflitamos sobre a questão.

Dispõe o art. 23 da Lei 6.649/79: “Art. 23. O locatário tem o direito de exigir do locador, quando este lhe entregar o prédio, relação escrita do seu estado". A regra é reprodução quase "ipsis literis" do art. 1.207 do Código Civil.

Comentando o supracitado dispositivo da lei codificada, explica CLÓVIS BEVII AQUA que, com a exigência da relação escrita do estado do imóvel, o inquilino "ressalva a sua responsabilidade", uma vez que tem o dever de restituir o prédio, no fim da locação, no estado em que o recebeu. E prosegue ensinando, "verbis": "O Código confere ao locatário o direito de exigir essa relação escrita, porque a vantagem maior é dele, que tem a responsabilidade de restituir o que recebeu, e esse documento constitui para ele uma garantia. Mas o senhorio terá, também, interesse na descrição do estado do prédio, para fundamentar as reclamaçōes, que tiver de fazer contra abusos ou extravios do locatário" (op. cit., vol. IV, pág. 387).

Trata-se, como é evidente, apenas de uma faculdade outorgada ao inquilino, que, embora esculpida pela lei para dar-lhe segurança probatória contra alegaçōes levianas do locador, pode perfeitamente deixar de ser exercida como ocorre freqüentemente na prática. E em tal hipótese, quer dizer, na falta de exigência da relaçāo pelo inquilino e posterior propositura de despejo pelo senho- 
rio fundado no mau uso, quem tem o ônus da prova? "Quid juris?" A esta pergunta responde enfaticamente o próprio CLÓVIS: "Presume-se que a coisa alugada se achava em bom estado, se do contrato não consta o contrário" (op. cit., vol. IV, pág. 363). E mais a frente reitera a interpretação da norma legal (art. 1.207 do C.C.) dizendo que se o locatário não fizer a exigência quando da contratação "entende-se que o recebeu em bom estado" (op. cit., vol. IV, pág. 387). É neste sentido, também, esta antiga, porém profícua, decisão do Tribunal de Alçada onde se lê: "Examine-se, pois, se, na espécie, os danos apurados se revestem de semelhante gravidade, justificardo-se até mesmo, desde logo, o rompimento do contrato de locação, evocando antes o princípio de que, s€: não existir ressalva respeitante ao estado do prédio, presume-se que ele foi entregue em bom estado de conservação (Rev. dos Tribunais, vol. 246/425)" (RT 358/349. Ap. 64.921, TASP, 4a. C.C., julg. em 23/12/1963, Rel. Juiz Pedro Augusto do Amaral).

6. Dúvida que merece esclarecimento, ainda no que diz respeito à infração ao dever de zelar e conservar o imóvel locado, é a relativa à possibilidade ou impossibilidade do senhorio promover ação de despejo por mau uso durante a vigência do cor trato, já que tem, ao seu final, ação indenizatória pelos estragos causados. E, tangenciando essa questão, poder-se-ia perguntar se, em caso positivo, poderia o locador cumular ao pedido de rescisão (despejo) o de indenização.

Quanto ao primeiro aspecto do questionamento levantado, parece ter ficado clara a nossa opinião a respeito em virtude de tudo que até aqui foi exposto. Contudo, e para que não remanesça qualquır dúvida, apresentamos, explicitamente, o fundamento doutrinário dessa posição.

Debruçando-se sobre o assunto, ensina CARVALHO SANTOS, cuja antiga lição é freqüentemente repetida pelos comentaristas, que: "Em regra, consoante a melhor doutrina, os danos devem ser ressarcidos, finda a locação. Não se trata, porém, de uma regra absoluta, por isso mesmo que se o dano atingiu a substância da coisa e for irreparável durante a locaçāo, o locador poderá, desde logo, pleitear o ressarcimento". E prossegue afirmando que "ainda que o dano seja atualmente reparável, se pela sua natureza ou pelas circunstâncias pode se transformar em prejuízo irreparável, dificultando o útil exercício da ação de indenização dos danos, ao locador é assegurado o direito de exigir imediatamente a indenização, assim como poderia pedir mesmo a resolução do contrato" (Código Civil Interpretado, Freitas Bastos, 6a. ed., 1955, vol. XVII, pág. 76 e 77). A lição referida ampara, ainda, o ensinamento de outro mestre, EDUARDO ESPINOLA, que reportando-se à jurisprudência de seu tempo assevera: “... os julgados têm firmado, com o prestígio das liçōes doutrinárias, não ser possível impor ao dono assistir, inerte, a séria danificação do seu bem, prenúncio de uma destruição, de um perecimento, que possa evitar, rescindindo a locação, 
com o despejo por mau uso, por deterioraçāo" (op. cit., pág. 215). Confiramse, neste sentido, os acórdãos insertos "in" RT 200/545, 358/348, este último fundado exatamente na doutrina acima exposta, e este outro cuja transcrição parcial do fundamento parece-no relevante: "... a obrigação de restituir a coisa locada em bom estado implica a de conservá-la com zelo e diligência. Assim como proprietário algum deixaria seu imóvel arruinar-se para depois repará-lo, da mesma forma o inquilino, que substitui o proprietário no encargo de conservação, não há de permitir que o prédio fique em estado ruinoso, para só então consertá-lo ao término do contrato ou quando houver de restituí-lo (Rev. dos Tribs. vol. 147/635). Por isso mesmo, de acordo com a melhor orientação, o mau uso durante a locação representa infração do locatário aos seus deveres normais" (RT 371/207. Ap. 78.031 TASP, 5a. C.C., julg. em 04/03/1966, Rel. Juiz Carvalho Filho).

Do mesmo modo manifesta-se SILVIO CAPANEMA DE SOUZA, comentarista da vigente Lei 6.649/79, que afirma incisivamente: "Se o locatário, durante o curso do contrato, deteriora anormalmente o prédio, ainda que nada se refira o contrato quanto à conservação do imóvel, estará ele infringindo obrigação legal, sujeitando-se ao despejo, com base no inciso II" (A Nova Lei do Inquilinato, Rio, Forense, 1979, pág. 284).

No que concerne à segunda dúvida suscitada, qual seja, a relativa ao cúmulo de ações (despejo e indenizatória), parece ter ficado suficientemente esclarecido, ante o teor dos ensinamentos trazidos à colação, que este é viável. Sobre o tema EDUARDO ESPÍNOLA já outrora afirmava: "Verificada a infração legal ou contratual, além da possibilidade de pleitear indenização de perdas e danos, se cabível, pode o locador propor o despejo" (op. cit., pág. 102). Mais recente, porém não menos precisa, é a lição de TUCCI-VILLAÇA: "Nada obsta, outrossim, a que a retomada do prédio alugado, em todos eles realizável mediante o ajuizamento da correspondente ação de despejo, se faça sob fundamentação em mais de um dos incisos do dispositivo estudado, cumulando-se, então, os pedidos formulados com lastro no disposto no art. 292 do Código de Processo Civil" (op. cit., vol. II, pág. 638). Sem dúvida, desde que respeitados os requisitos de compatibilidade (como visto existente entre os pedidos de rescisão e indenização), competência e identidade procedimental, não há o que impeça o cúmulo de ações, o que se vem admitindo, inclusive, quando um dos fundamentos seja a falta de pagamento (RT 323/474; 320/414; 312/646; $310 / 288$ ). O que não se dizer das outras hipóteses em que o rito ordinário é o único cabível sem qualquer modificação. Exemplificativamente veja-se a emenda deste acórdão: "Ação de despejo - Cumulação com pedido de rescisão do contrato e perdas e danos - Possibilidade, desde que o autor opte pelo processo de cognição e, neste, pelo procedimento ordinário" (Jurisprud. Brasileira 100/184. Agr. 143.925, II TACSP, julg. em 13/09/82, Rel. Juiz Fortes Barbosa). 
7. Por derradeiro, queremos chamar a atenção para o fato de que, perante o. sistema da Lei 6.649/79, não necessita o locador notificar previamente o locatário - dando-lhe a oportunidade para reparar o imóvel quando tencione mover-lhe ação de despejo por mau uso do prédio locado. A bem da verdade, em nenhuma das situações prevists pelo art. 52 da Lei do Inquilinato é necessário o envio prévio de notificação para que se possa acionar o inquilino; em todas elas o interesse de agir, condição de exercitabilidade do direito de ação, verifica-se no exato instante em que a hipótese fática ensejadora do despejo acontece.

Neste sentido é o escorreito magistério de PAULO RESTIFFE NETO, escrevendo especificamente acerca do tema (Locação-Questões Processuais, Ed. RT, 1981, 2a. ed. pág. 18), em consonância com o qual o II Tribunal de Alçada Civil de São Paulo, em 1985, proferiu a seguinte decisão: "Despejo - Imóvel residencial - Notificação - Inexigibilidade. A lei 6.649/79 não exige que a ação de despejo de imóvel residencial, fundada nas hipóteses alinhadas em seu art. 52, seja precedida de notificação" (JTA-RT 99/325. Ap. 181.591, 2a. C. II TACSP, julg. em 20/05/85, Rel. Juiz Moraes Sales).

São Paulo, dezembro de 1989. 